\title{
CAPÍtulo V \\ ¿CuÁl ES LA IMPORTANCIA DE LA EPISTEMOLOGÍA, EN TANTO QUE MATERIA HUMANÍSTICA, PARA EL ESTUDIANTE DE LA ÉPOCA ACTUAL?
}

Manuel Prada Rodríguez ${ }^{1}$

\section{Introducción}

En el texto se explica y ejemplifica la clásica diferencia que hay entre conocimiento y opinión; se muestra la importancia de abandonar la ingenuidad con la cual nos educa la sociedad para adquirir pensamiento crítico; se tocan tangencialmente algunas teorías de la verdad, enfatizando la diferencia entre esta última y la validez; se advierte de la preponderancia de las presuposiciones a la hora de interpretar el mundo; se muestran algunos conceptos desde otra perspectiva y se promueve la diversidad de saberes, rechazando las visiones hegemónicas y excluyentes de las demás.

1 Teólogo y magíster en Filosofía Latinoamericana de la Universidad Santo Tomás. En la actualidad, es profesor del Departamento de Humanidades y Formación Integral de la Universidad Santo Tomás. 
Lo anterior está pensado como un abrebocas a la materia de epistemología que el Departamento de Humanidades y Formación Integral de la Universidad Santo Tomás ofrece a los estudiantes, con el fin de mostrar su utilidad. Aprender a preguntar para cuestionar la realidad y no aceptar discursos con prontitud, antes de revisar si son superficiales (doxa) o profundos (episteme), son algunas de las herramientas que los estudiantes adquieren, en el marco de una universidad de estudios generales, de pensamiento dominicano, lo cual implica ligar siempre los intereses académicos con la realidad.

\section{La epistemología como descubrimiento}

Para comenzar a contestar la pregunta orientadora de este ensayo, es pertinente explicar brevemente que la epistemología es una rama de la filosofía. Entre muchas otras definiciones, una de las más clásicas dice que la filosofía es la búsqueda de explicaciones coherentes y debatibles acerca del mundo de los hechos, pero no a partir de los detalles específicos, como lo hacen las ciencias, sino desde las ideas generales, como lo hace la geometría. Se trata de una investigación por las causas últimas o principios del mundo de los hechos, por el qué es la cosa y no solo por el cómo funciona y qué gano de eso - preguntas que parecen ser las únicas relevantes en la actualidad, dada la influencia de la ética utilitarista en las acciones de la vida cotidiana; no obstante, paradójicamente, la ética utilitarista que está tan de moda en la actualidad, también hace parte de la filosofía-. Pero antes de preguntar ontológicamente -es decir, cómo está organizada la realidad, según nuestra manera cultural de pensar- qué es la cosa, con el fin de dar una respuesta bien fundamentada y no fantasiosa, la epistemología cuestiona primero si es cierto que existe eso que damos por sentado, sin cuestionarlo jamás, y que denominamos "realidad". La epistemología también indaga la posibilidad de conocerla; cómo está constituido nuestro pensamiento, nuestra percepción; entre otros asuntos relacionados con la adquisición del conocimiento, tal como lo menciona Jonathan Dancy,

La epistemología es el estudio del conocimiento y de la justificación de la creencia. Entre las cuestiones centrales a las que tratan de responder los epistemólogos están: “¿qué creencias están justificadas y cuáles no?”, “si hay algo que podemos conocer, ¿qué es?”, “¿cuál es la relación entre conocer y tener una creencia verdadera?”, “¿cuál es la relación entre ver y conocer?”. ${ }^{2}$

2 Jonathan Dancy, Introducción a la epistemología contemporánea (Madrid: Tecnos, 1993), 15. 
Por ser una rama de la filosofía, la epistemología también indaga por la totalidad. En ese sentido, si, por ejemplo, un joven que recientemente ha egresado del colegio asiste a un curso preuniversitario para conocerse mejor y con el fin de adquirir un criterio firme para poder elegir el pregrado que más le conviene, que más se ajusta a su personalidad, intereses, afinidades, etc., y se da cuenta de que lo suyo es estudiar psicología, debería preguntarse primero qué significa la palabra que intitula dicha disciplina; si existe eso que se conoce como psiquis, es decir, si es ubicable en alguna parte del cuerpo o es más bien una palabra sin referente en el mundo de los hechos; si la psicología pertenece al grupo de las ciencias o de las humanidades o de los saberes populares, etc. En otras palabras, se sugiere al candidato a un pregrado que vea a este último desde el conjunto, no solo desde la ilusión fragmentaria de que en algún momento dicho saber le generará dinero. Esta última actitud, que es poco humanista porque no valora el trabajo como un posibilitador de la realización voluntaria del ser humano, sacando lo mejor de sí en la actividad que elige realizar por la felicidad que le produce, sino que reduce todo a términos monetarios, es ocasionada, quizás, porque la academia ya no es un fin en sí mismo o porque los padres de familia no apoyan lo que creen son causas perdidas, como la música o la filosofía, entre otras carreras inútiles -realmente las humanidades son inútiles porque, valga la redundancia, no tienen utilidad, ya que no son técnicas, no sirven para hacer algo físico y obtener ganancias, sino formas para evaluar el mundo de los hechos con ojo crítico y poder tomar decisiones bien pensadas en la vida-. Otra posible explicación es que los estudiantes de ahora son hijos de su mundo, de su época tecno-científica, de una racionalidad instrumental que no piensa el conocimiento, sino que lo usa para sacar beneficio económico de él. El caso es que dicha actitud refleja carencia de pensamiento crítico, de aceptación ingenua de la interpretación hegemónica del mundo de los hechos, impuesta por quienes son dueńos del conocimiento y, por tanto, del poder. ¿Vale la pena vivir así?, la siguiente cita explica mejor qué es el pensamiento crítico:

¿Qué es para usted el pensamiento crítico?

Se pueden atribuir dos acepciones al término "crítica". En primer lugar, una acepción que podría denominarse kantiana, que designa, en la línea del pensamiento del filósofo de Königsberg, el examen evaluativo de las categorías y formas de conocimiento con el fin de determinar su validez y su valor cognitivos; en segundo lugar, una acepción marxiana, que se dirige con las armas de la razón hacia la realidad sociohistórica para sacar a la luz las formas ocultas de dominación y de explotación existentes, con el fin de hacer aparecer, en negativo, las alternativas que dichas formas obstruyen y excluyen (Max Horkheimer definía como "teoría crítica" aquella teoría que es a la vez explicativa, normativa, práctica y reflexiva). A mi juicio, el pensamiento crítico más 
fructífero es el que se sitúa en la confluencia de estas dos tradiciones y que, por tanto, une la crítica epistemológica y la crítica social, cuestionando de forma constante, activa y radical las formas establecidas de pensamiento y las formas establecidas de vida colectiva, el "sentido común" o la doxa (incluida la doxa de la tradición crítica), y las relaciones sociales y políticas tal como se establecen en un determinado momento en una sociedad dada. ${ }^{3}$

El problema de esta actitud ingenua, que lleva a la persona a decidir invertir tiempo y recursos económicos en estudiar algo sin tener al menos una idea panorámica de la disciplina que se va a elegir, es que impide ver a los futuros egresados la diferencia que hay entre ser un charlatán (doxa) y un profesional (episteme). Es decir, si el alumno sigue esperando que el profesor lo lleve de la mano, diciéndole heterónomamente lo que tiene que hacer, entonces, seguramente, dicha persona en el futuro será un profesional mediocre, que habla de lo que sabe a medias, de lo que más o menos conoce, pero no está seguro. Sus palabras, entonces, son pura ilusión, encanto, publicidad, más no profundidad. El siguiente ejemplo puede ayudar a entender mejor la diferencia que hay entre episteme y doxa.

Hay muchas personas que, sin que sus interlocutores se lo pidan, los aconsejan. Creen saber mucho sobre la vida y tener la capacidad mágica para identificar de inmediato las causas de los problemas. En esas conversaciones, es común escuchar dichos como: "no, usted lo que tiene es... por tanto, siga esta receta...". Pero sentir empatía hacia el otro y atreverse a darle un consejo no son acciones suficientes para que dicha persona pueda ser catalogada como psicóloga. Por orientar a otra persona en un momento dado de su vida, ¿tiene derecho a ser reconocida epistemológicamente como consejera? En Cultura Física sucede algo semejante. Muchas personas creen que la función de los profesores de educación física es muy fácil porque solo consiste en llevar a los estudiantes al parque, para que jueguen con un balón. Pero ¿quién dice que tener la capacidad de entretener a alguien es igual a tener la destreza bien lograda de saber entrenarlo? Si un tegua sabe sobar piernas golpeadas, ¿¿debo confiarle a sí no más la que tengo afectada?, si él me lesiona más, en lugar de curarla, ¿quién va a responder por ese daño, si él no tiene título ni tarjeta profesional que lo acrediten epistemológicamente como una persona conocedora del tema? Por lo anterior, es posible decir que la epistemología tiene que ver, también, con la normatividad y los procesos que una persona debe seguir para adquirir una nombradía, de tal manera que a la comunidad que se beneficia de dicho conocimiento, le parezca que este es confiable, fuerte,

3 Loïc Wacquant, Pensamiento crítico y disolución de la doxa: entrevista con Loïc Wacquant, Antípoda. Revista de antropología y arqueología No 2 (2006): 44. 
sólido, bien adherido a la mente y no dudoso, como sucede a menudo con la información efímera. La epistemología marca la diferencia entre un profesional excelente y uno de dudosa reputación y confiabilidad. Sin embargo, al mismo tiempo, la epistemología va dejando atrás, fuera del tren del progreso característico de la modernidad y de uno de sus más claros exponentes, la Revolución Industrial, los saberes ancestrales que, por no poder cumplir con las normas de certificación, deben ser consideradas como opiniones o saberes populares.

Claro, hablar maravillas de tal pastilla para la gripe, porque a dicha persona le funcionó, no hace de ella una medicina apta para recetar. Pero el taita, el paco, el yatiri, el chamán, el sabio de la comunidad ha heredado, por tradición oral y experiencia, un conocimiento que, aunque no ha pasado por un proceso de validación en un laboratorio, es efectivo. ¿ Hay que arrojar a la basura nuestros saberes ancestrales solo porque lo que está de moda es la ciencia y no el mito? La episteme que sirve para excluir debe ser replanteada, porque, dado que el conocimiento es político, esa postura epistemológica torna excluyente a la política. Y, tristemente, así es la realidad. Por eso sería bueno pensarla y buscar modificarla, para poder disfrutarla mientras se la vive, convirtiéndola en más incluyente, permitiendo la unión de los opuestos, en lugar de seguir promoviendo la mutua exclusión, siguiendo fanáticamente al principio lógico de no contradicción, como si este fuera la verdad absoluta. Hay que empezar a hablar en términos de lógica paraconsistente, más aún cuando los latinoamericanos, por nuestro trasfondo indígena, pensamos así, contradiciéndonos todo el tiempo sin que nada pase, sin que el sistema se trivialice.

\section{La epistemología como desenmascaramiento y superación de la tesis general de la actitud natural}

Ahora bien, el hecho de que haya gente que anda por ahí sin interesarse por conocer a fondo aquel mundo simbólico que habita, no es un problema exclusivo de algunas personas que apenas empiezan a estudiar un pregrado. También lo es de algunos profesionales. Incluso, de algunos que están relacionados con las ciencias, sean famosos o no. Ellos, no todos, por supuesto, presuponen que el mundo de los hechos existe y que es analizable, sintetizable, transformable, desbaratable, renovable, entre otras cualidades que casi siempre lo ponen a merced de los caprichos económicos de las personas poderosas que financian sus proyectos de investigación. En otras palabras, un astrónomo no se preguntaría, tal como lo haría René Descartes, si la luna existe o si ese círculo que se ve en el cielo y que es conocido como satélite natural no es más que una alucinación 
causada por un genio maligno o un hongo. No. Mientras que el epistemólogo usa la fantasía para trazar hipótesis e imaginar su verificación o falseación, es decir, para andar en la imaginación por el camino supuesto, a ver si por medio de pasos lógicos se puede llegar a la meta o no, o sea, al cumplimiento del objetivo de la investigación, algunos profesionales relacionados con las ciencias tienden a ceñirse drásticamente a los hechos de la realidad, creyendo que su actitud es pura, libre de suposiciones, totalmente apta para una investigación objetiva. Según ellos, no hay nada que se interponga entre su mente y el objeto de estudio que les interesa. No hay nada en su mente que distorsione o altere los datos empíricos. ¿No es esto ingenuidad?

Empero, así no sean conscientes de ello, la mayoría de profesionales relacionados con las ciencias comienza sus investigaciones partiendo de un campo delimitado de estudio y de una creencia a ciegas en la existencia de dicho objeto. A esto se le conoce como positum, de donde viene la palabra "positivismo", término que conglomera a las ciencias. Esta palabra latina es sinónima de lo a priori; lo formal; lo axiomático - de donde se derivan los teoremas-, es decir, los principios fundamentales que sirven de principio o punto de partida de un sistema lógico de pensamiento; lo presupuesto; lo dado de antemano; la noción que está en la mente antes de que se haya experimentado a través del cuerpo, es decir, de que se haya verificado:

Una ciencia está formada por un conjunto de juicios que se refieren a una región de los entes. Debido a esta referencia, los juicios -toda ciencia tiene un carácter sistemático- deben tener en cuenta la manera de ser de la región correspondiente. De manera que la estructura de una ciencia está determinada por la estructura de la región a que se refiere.

Pero los entes en total eran originariamente una unidad. Hay que suponer, por consiguiente, que la división en regiones fue el resultado de un acotamiento. Las ciencias se reparten los entes recortándolos, por decirlo así, en trozos. Estas imágenes - “recortar" y "trozo”- las emplea ya Aristóteles. Pero no son exactas. Pues no se trata propiamente de cortes, sino de una constitución. La constitución se lleva a cabo por medio de un plan previo, en el cual se esboza de antemano la estructura de la región. Esto parece paradójico, pero es así. Antes de que una ciencia se pueda dedicar a investigar cómo son los objetos de su dominio, tiene que saber qué son ellos. Sin este saber no podría distinguir sus objetos de los ajenos; es más, ni siquiera podría encontrarlos, porque se le desvanecerían en la niebla indiferenciada de los entes en total. ${ }^{4}$

4 Danilo Cruz Vélez. (2001). Filosofía sin supuestos. Manizales: Universidad de Caldas. p. 226. 
Esto quiere decir que mientras algunos profesionales que trabajan en asuntos científicos se preocupan demasiado por llegar a el mundo de los hechos, no se dan cuenta de los supuestos que tienen en su mente y que les hacen considerar a esos fenómenos que ellos, gracias a la percepción, tienen en su memoria como si se tratara del mundo de los hechos mismo. Ellos no saben, o no les interesa conocer, la diferencia que hay entre fenómeno y noúmeno, entre lo que percibimos de la cosa y la cosa misma. Ellos no se inquietan por distinguir entre sus percepciones y el mundo de los hechos, sino que asumen que el mundo de los hechos es tal cual como la perciben, bajo la creencia de que no puede haber mayor margen de error si se utiliza un instrumento de precisión en la experimentación, tal como un telescopio. ¿Qué puede estar equivocado en mi observación de la luna, si las lentes de este telescopio son de última tecnología? sería una pregunta que alguno de ellos podría realizar. Como si se tratara de una religión experimentada desde el fanatismo y no desde la equilibrada religación, algunos profesionales de las ciencias se acostumbran a depositar su fe en la doctrina de la exactitud, vista como ausencia casi total de error, como la búsqueda del $99.9 \%$ de probabilidad en sus ensayos. De lo que no se dan cuenta es que, por más que se tenga esta fe, la exactitud es simplemente una construcción mental que no anda suelta en el mundo de los hechos. Dicho dogma, que no se puede cuestionar porque la religión de Comte lo prohíbe, es una interpretación de un hecho, pero no el hecho en sí. En otras palabras, la epistemología sirve para advertir al científico cuando este nada, sin saberlo, en la actitud natural. Para entender de qué se trata dicha actitud, conviene citar a René Descartes, quien comienza su segunda meditación metafísica, así:

La meditación de ayer me ha sumido en tan grandes dudas, que ya no puedo olvidarlas, pero no veo cómo resolverlas; sino que me encuentro tan turbado como si de repente hubiera caído en un profundo remolino de agua y no pudiera hacer pie ni nadar hasta la superficie. Pero me esforzaré e intentaré de nuevo la misma vía que emprendí ayer, apartando todo lo que admite la más mínima duda, como si hubiera descubierto que es completamente falso; y seguiré adelante hasta que conozca algo cierto, o bien, si ninguna otra cosa alcanzo, al menos admitiré como cierto que no hay nada cierto. Arquímedes solo pedía un punto, que fuera firme e inmóvil, para cambiar de lugar la tierra entera; también yo podré esperar mucho si logro encontrar algo, por pequeño que sea, cierto e incuestionable.

Supongo, pues, que todas las cosas que veo son falsas; creo que nunca ha existido nada de lo que me representa la mendaz memoria; no tengo sentidos; el cuerpo, la figura, la extensión, el movimiento y el lugar son quimeras. ¿Qué será, pues, verdadero? Quizá solo esto: que no hay nada cierto. Pero ¿̨cómo sé que no hay nada diferente de todo lo que acabo de examinar, sobre lo 
cual no haya ni la más mínima ocasión de duda? ¿Es acaso algún Dios, o como se le quiera llamar, quien pone en mí estos pensamientos? ¿Por qué pienso esto, cuando quizá puedo ser yo mismo su autor? Pero ¿soy yo algo, acaso? Ya he negado que tenga sentidos y cuerpo. Sin embargo, me quedo indeciso; pues ¿qué se sigue de ello? ¿Acaso estoy ligado de tal manera al cuerpo y a los sentidos que no puedo ser sin ellos? Me he convencido de que no hay nada en el mundo: ni cielo, ni tierra, ni mentes, ni cuerpos; pero ¿̇me he convencido también de que yo no soy? Ahora bien, si de algo me he convencido, ciertamente yo era. Pero hay cierto engañador, sumamente poderoso y astuto, que, de industria, siempre me engańa. Ahora bien, si él me engaña, sin lugar a dudas yo también existo; y engáñeme cuanto pueda, que nunca conseguirá que yo no sea nada mientras piense que soy algo. De manera que, habiéndolo sopesado todo exhaustivamente, hay que establecer finalmente que esta proposición, Yo soy, yo existo, es necesariamente verdadera cada vez que la profiero o que la concibo. ${ }^{5}$

Los seres humanos, al relacionarnos con nuestro mundo circundante mediante las representaciones, los juicios, los sentimientos, los valores y las querencias, nos encontramos en una situación prefilosófica. En dicha actitud, el yo no presta atención a sí mismo, solo presta atención al mundo. En ese estado de enajenación, distracción o falta de atención en nosotros mismos, creemos ingenuamente que dicho mundo existe realmente. Al respecto, las siguientes palabras de Danilo Cruz Vélez:

La nota fundamental de los actos es la intencionalidad. Todo acto es intencional, apunta hacia un objeto, tiene un intentum. Según esto, debemos ver los actos ejecutados en actitud natural a la luz de la intencionalidad. ¿En qué consiste, pues, la referencia intencional a las cosas cuando se hace en actitud natural? La referencia en actitud natural tiene el carácter de una intentio recta. En ella el yo va directamente hacia los objetos, sin atender a nada más. El yo se pierde en las cosas y se olvida de sí mismo. En la actitud natural el yo está, pues, olvidado. Las cosas son lo real, lo existente. La actitud natural es precisamente una fe ciega en la realidad de las cosas. ${ }^{6}$

Esta es la tesis general de la actitud natural, en la cual, por voluntad propia, ponemos al mundo como existente. Pero, también por voluntad propia, podríamos rechazar esa creencia. Es solo que si negáramos libremente la existencia del mundo, negaríamos, necesariamente,

5 Rene Descartes, Meditaciones metafísicas y otros textos. (Madrid: Editorial Gredos, 1987), 21-22.

6 Cruz Vélez, Op. Cit., 253. 
la existencia del yo, porque este último: "consiste en un conjunto de actos intencionales que apuntan a los objetos mundanos" . Por consiguiente, al negar tanto al mundo como al yo que se fija en él, se niega de paso esa relación que hay entre el yo y su mundo circundante. Pero sin esa relación, no habría ni actitud natural ni nada. Y tal aseveración sería puro escepticismo. Para no caer en ello, el epistemólogo piensa. Este último no necesariamente debe ser científico, porque no le interesa hacer ciencia, sino encontrar los fundamentos de la misma, criticando sus procedimientos, paradigmas, creencias, etc. Es decir, el epistemólogo es como el comentarista de fútbol que, sin tener dominio de balón ni habilidad para gambetear, habitualmente sabe más de dicho tema que un futbolista, porque posiblemente está mejor documentado que él.

Solo el epistemólogo, que está acostumbrado a indagar en su interior, a reflexionar, a pensar en sus gustos, pasiones, desamores, virtudes, vicios, entre las demás características que componen lo que aristotélicamente se conoce como la substancia de "humanidad", es capaz de indagar en su subjetividad para conocer cuáles son sus supuestos, es decir, sus creencias, compuestas por las experiencias de vida que ha ido acumulando a lo largo de su existencia, sin importar si esta es auténtica o no, en términos heideggerianos. Claro, a veces esos supuestos no se basan en experiencias, sino en enseñanzas que otros han dado o ideologías que otros han impuesto, por medio de la publicidad, sin que la persona se dé cuenta de ellas, operando mental y prácticamente con ellas como si se tratara de algo natural. Esto hace que el epistemólogo, a diferencia del científico que instrumentaliza el conocimiento sin reflexionar sobre él, tenga algo más de libertad en su propuesta investigativa. Lo que más importa en las ciencias es el método que se usa para garantizar la objetividad. En las epistemologías (porque hay varias, incluso emergentes, indígenas, africanas, femeninas, del sur, de la periferia, etc.), por el contrario, el método es eso, un conjunto de pasos para llegar a la meta de conocer la subjetividad y entablar una relación de correspondencia entre ella (gustos, afinidades, pasiones, reacciones, personalidades, etc.) y el tema a investigar. Es decir, en la época en la que estamos inmersos, prácticamente solo el epistemólogo se atreve a hacer lo que le llena, lo que le gusta, lo que da sentido a su vida, mientras que los profesionales que tienen algo que ver con la ciencia están tentados constantemente a investigar lo que más les conviene, hablando en términos de fama o rentabilidad económica. Ellos, dudosamente, buscan la felicidad a través de las acciones, aunque esto no es una generalidad, dado que las mentes científicas más brillantes han disfrutado al máximo sus investigaciones, incluso sus fracasos, como lo hacía Thomas Alva Edison.

\footnotetext{
7 Ibíd. 18.
} 
Lo anterior es una de las preocupaciones del pensamiento dominico, que hunde sus raíces en Aristóteles, tan caro para Santo Tomás de Aquino, quien consideraba que el fin último de la vida era la búsqueda de la felicidad. El Departamento de Humanidades y Formación Integral, a través de la cátedra de epistemología, busca posibilitar a los estudiantes el conocimiento de sí mismos, mostrando con claridad los elementos doxológicos de la cultura que poco aportan al crecimiento epistémico-intelectual-cognoscitivo de la persona, que, siendo perfectible, hoy en día está sometida a la atrofia de su mente, causada por las manipulaciones mediáticas que le impiden pensar por sí misma. Claro, esta felicidad no equivale a consumismo, a cualquier criterio de dicho concepto que maneje la opinión popular. La epistemología busca, por el contrario, que la persona alcance la felicidad por medio del escape de la opinión de la masa, a través de la postura propia, crítica y bien documentada. En ese sentido, ser feliz consiste en que al estudiante ya no lo estafen con cuentos bien elaborados, sino que él, por saber discernir entre un discurso válido y otro inválido, decida qué acepta y qué no porque no le conviene.

El epistemólogo enfoca sus esfuerzos en comprender la forma y el contenido de su conocimiento, en saber el para qué (telos, finalidad), pero comenzando por el qué (ousía, que ontológicamente significa substancia, aunque morfológicamente, esencia), mientras que al científico le interesa más la techné, que significa técnica, desocultamiento, pasos para llegar a la verdad que se busca, con el objetivo de llegar a la meta, pero sin importarle en verdad qué quiere lograr. Así de etéreo e informe es el progreso, que no sabe lo que persigue y que quizás está dando giros a toda velocidad sobre su propio eje, alucinado avanzar hacia una dirección, cuando lo que está haciendo es moviéndose desenfrenadamente.

\section{La epistemología une a la metafísica con la ontología, a través de la hermenéutica}

El científico afirma -porque así lo cree con esa certeza que epistemológicamente se opone a la duda, excluyendo cualquier otro punto de vista mediante la maltratante designación de "pensamiento pseudocientífico"- que la tierra gira en torno al sol en un recorrido que dura un año. En este caso, a él no le interesa ver nada más allá-metafísico- de la tierra, el sol, la distancia que hay entre ellos, el tiempo que dura el movimiento de traslación, entre otros datos fácticos. Ahora bien, ¿qué es lo que ve el epistemólogo, cuyos análisis holísticos no pueden descuidar la metafísica, la ontología, la hermenéutica, la política, entre las demás ramas de la filosofía que 
ayudan a comprender la totalidad del mundo? El epistemólogo ve lo que el científico no: una vez más, que el mundo de los hechos no es tal cual como lo percibimos. Las percepciones sensoriales a veces son decodificadas por el cerebro como datos contradictorios. Por ejemplo, según el sentido de la vista, un queso fino se ve delicioso, pero según el sentido del olfato, huele mal. Dado que el cerebro no tiene características intrínsecas que le permiten acceder directamente al mundo de los hechos, sin necesidad o aparte de los sentidos, no tiene cómo juzgar cuál sentido es el que tiene la verdad, si la vista o el olfato. La mente no tiene manera de saber cuál orden darle al sentido del gusto, si probar el queso o no. En este caso, estamos hablando de la verdad correspondentista, que es un tipo de verdad entre muchos otros, tales como el coherentismo o el desocultamiento.

El correspondentismo afirma que para que un enunciado sea verdadero, debe coincidir con lo que sucede en el mundo de los hechos. Es como la esperanza que el pueblo tiene cuando escucha al político que le endulza el oído: ojala cumpla todo lo que promete. Aplicada al ejemplo, la teoría de la verdad como correspondencia entre el enunciado y el hecho nos permite darnos cuenta de que la mente no tiene cómo saber cuál sentido dice la verdad, que se queda sin conocer a ciencia cierta si el queso sabe bien o mal, porque la verdad consiste en una correspondencia entre el dato y el hecho, es decir, entre el conocimiento que está adentro del cerebro y los datos caóticos que vienen a él desde afuera, desde el mundo de los hechos, gracias a la percepción sensorial, y que hay que organizar mentalmente. Pero, como se ha dicho, la mente está encarcelada en el cuerpo, sin poder salir a darse un paseo por el mundo de los hechos. No obstante, aun así, ella se atreve a evaluarlo; a decir si le gusta o no, si es verdadero o falso; entre otros juicios emitidos a través del lenguaje. ¿¿n qué se basa, entonces, la mente para juzgar así el mundo de los hechos si no tiene, digámoslo, autoridad moral para hacerlo, conocimiento de causa, acceso directo a ese mundo de los hechos?: en, exactamente, sus presuposiciones. En la capacidad apriorística de trazar hipótesis para imaginar qué sucederá en el futuro, si dicho camino se anda. En ese sentido, mientras el científico cree estar girando alrededor del sol, por cuanto mora en este planeta que "obvia" e "indubitablemente" ejerce su movimiento de traslación, el epistemólogo piensa que el científico simplemente está compartiendo el punto de vista de Copérnico, que es una forma de explicar el mundo de los hechos, entre otras más. Así las cosas, el epistemólogo, partiendo del hecho de que también existe la teoría geocéntrica de Ptolomeo, sabe que el científico no dice la verdad absoluta, la única que existe, sino que más bien, partiendo de sus presuposiciones, está emitiendo un discurso válido durante este tiempo histórico, entre muchos otros que también deberían ser considerados en la modernidad como válidos, tales como la mitología. Además, el epistemólogo sabe que en algún momento la visión copernicana será rebatida, tal como lo fue la ptolomeica, por lo cual eso que hoy en día se conoce como la verdad es contextual, temporal, no eterna, sino 
mutable, según las necesidades que los seres humanos vayan teniendo acerca de las explicaciones, para sentirse convencidas. En épocas de crisis, hay paradigmas que ya no convencen, que dejan a las personas en crisis, sin saber a qué base epistemológica agarrarse. Es en ese entonces cuando hay que superar la crisis, eligiendo nuevos fundamentos, más acordes con lo que se piensa y se quiere pensar en ese momento.

\section{De la verdad como visión unívoca del mundo a la validez como expresión de la diversidad de posturas}

La epistemología sirve -aunque no tiene fines prácticos ni fácticos-, por consiguiente y entre otras cosas, para que los profesionales de áreas relacionadas con la ciencia sepan que existe una diferencia entre validez y verdad, entre falsedad y falacia. La verdad tiene que ver con contenidos del mundo de los hechos: "el carro es verde". La falsedad, con la falta de correspondencia entre los enunciados y el mundo de los hechos, entre lo que se dice y lo que es: "el carro no es verde, es rojo". En cambio, la validez no toca al mundo de los hechos, de los contenidos, sino que simplemente se relaciona con las formas. No le interesa saber si el carro es verde o rojo, sino que $S$ es P. La variable "S", como en álgebra, puede ser reemplazada con cualquier contenido. Lo mismo sucede con "P". El interés de la lógica se centra, en este caso, en la relación que hay entre $S$ y P, no entre el vehículo y su color. O sea, el epistemólogo, que acude a cada momento a la lógica formal, está pendiente de las diferencias de orientación que hay entre los conectores de las proposiciones, para poder entender el sentido de un texto. ¿Se está diciendo "S es P" o "si S, entonces P" o "S y P" o "S o P"? El sentido de una oración cambia mucho, dependiendo del conector que se use entre las partes de la misma. ¿Se está usando en el discurso una igualdad, una implicación, una conjunción o una disyunción?, ¿el autor está comparando, derivando, relacionando o contrastando?, mejor dicho, ¿qué está haciendo el autor con su manera de organizar las palabras para convencerme de su tesis central? la epistemología también se enfoca en el proceso, en el cómo se dice, cómo se hace, no solo en los resultados. Por eso contribuye mucho a la ciencia en lo concerniente al método científico para aproximarse al mundo de los hechos.

¿De qué sirve conocer la diferencia entre validez y verdad? Si yo estoy en cuarto de primaria, escuchando de mi profesora de historia que 1492 es la fecha del Descubrimiento de América, aprendo que esa es la verdad. O sea, hubo un hecho: los españoles llegaron a un territorio poblado por personas desde muchos milenios atrás, y a ese hecho los españoles $-\mathrm{y}$ el resto del 
mundo occidental- lo llamaron "descubrimiento". Su interpretación del hecho fue optimista. No obstante, ¿qué podría pensar una indígena o una africana acerca de ese mismo hecho? que, lejos de ser un descubrimiento, es una violación a los Derechos Humanos, por más anacrónico que suene este calificativo. Que se trata de un genocidio, de la explotación de la tierra y los esclavos, entre otras cosas que difícilmente encajan en el concepto "descubrimiento". Pero si yo escribo en la respuesta del punto de la evaluación que pregunta por 1492, que se trata de una masacre cometida por mercenarios españoles, mi nota será: 0.0 , porque mi respuesta no coincide con la interpretación oficial del mundo de los hechos, es decir, con ese punto de vista que es considerado por los espańoles, que lograron el poder con la fuerza, como el único posible. La verdad, entonces, deja de ser la única relación posible entre los enunciados y las cosas, para llegar a ser una elección caprichosa de quien ostenta el poder. Al respecto, Friedrich Nietzsche explica lo siguiente:

\begin{abstract}
¿Qué es entonces la verdad? Una hueste en movimiento de metáforas, metonimias, antropomorfismos, en resumidas cuentas, una suma de relaciones humanas que han sido realzadas, extrapoladas y adornadas poética y retóricamente y que, después de un prolongado uso, un pueblo considera firmes, canónicas y vinculantes; las verdades son ilusiones de las que se ha olvidado que lo son; metáforas que se han vuelto gastadas y sin fuerza sensible, monedas que han perdido su troquelado y no son ahora ya consideradas como monedas, sino como metal ${ }^{8}$.
\end{abstract}

Basándonos en esto podemos afirmar que la lógica nos lleva al reconocimiento de que existen otras posturas que también explican coherentemente un mismo hecho, siguiendo las normas lógicas para organizar la información y derivar nuevos datos, es decir, encasillando los datos empíricos en las formas puras de la lógica, metiendo y encajando la palabra "carro" en "S" y "verde", en "P", para ver qué relaciones se dan entre esos términos. Desde ahí, ya no es posible decir que la proposición "1492 es la fecha del Descubrimiento de América” es verdadera, sino que es válida, así como también lo es la que reza: "1492 es el inicio del asesinato fáctico e inmaterial o cultural, de diferentes poblaciones indígenas y africanas".

Lo anterior se relaciona con los estudiantes de epistemología que proceden de microsociedades donde se sigue una moral estricta y se afirma que solo hay una posible explicación de los hechos. En epistemología son frecuentes las clases donde se presentan disonancias cognitivas, que llevan a los estudiantes a cuestionar su propio entorno, las normas de su hogar, los preceptos de su credo

8 Friedrich Nietzsche, Sobre verdad y mentira en sentido extramoral. (Madrid: Tecnos, 1998), 25. 
religioso, etc. Pero esto no implica un llamado al desenfreno o a la ausencia de moral, sino a la revisión crítica de la misma. Es decir, la epistemología motiva a los estudiantes a pasar desde la moral, entendida en este caso como el cumplimiento estricto de normas, a la reflexión sobre ellas, para decidir cuáles cumple y cuáles no, porque se ajustan o no a su conciencia. En otras palabras, en epistemología se privilegia el paso desde la heteronomía hasta la autonomía, desde la minoría de edad hasta la mayoría de edad, enfatizando la idea de que el ser humano no es una cosa, por lo cual puede objetar conciencia cuando alguien intente obligarlo a tomar una decisión con la cual no está de acuerdo. Pero esto no significa que las clases de epistemología estén al servicio del positivismo, erradicando cualquier destello de fe con la premisa de que este es retrógrado. En esta materia se da paso a las epistemologías emergentes, a las visiones indígenas, asiáticas y africanas de la realidad, no solo las eurocéntricas.

En esa misma línea de pensamiento, en la antigüedad griega la felicidad se llamaba eudaimonía, es decir, buen demonio. Si yo estoy triste, pero después me alegro, surge la pregunta: ¿qué fomentó ese cambio emocional? La explicación más coherente en una época o mundo mitológico es que se me metió un demonio, pero no malo, sino bueno, que desde el interior me hizo cambiar el malgenio. Él, que es bueno, combatió, aunque no en términos maniqueos, al genio maligno. Hoy en día, la ciencia se burla de esa explicación, diciendo que es arcaica, retrógrada, anticuada, poco actual y para nada verosímil. ¿Qué explica, a cambio? Que la alegría se debe a una sustancia química que reside en el cuerpo humano y que se conoce como serotonina. Cuando esta escasea, uno se siente de mal genio. Pero si uno ingresa dicho componente a su cuerpo comiendo un chocolate, entonces el metabolismo es alterado, haciendo que la persona adquiera síntomas de alegría. ¿ No podríamos decir, en este caso, mitológicamente hablando, que el científico está proponiendo una posesión serotoniniana, así como en la antigüedad griega se decía que se trataba de una posesión demoniaca, aunque buena?, ¿̨no podríamos decir, de manera similar, científicamente, que al interior de la persona triste ingresó una pastilla, cuyo slogan publicitario es: "Ángel. La pastilla que mata a tus malos demonios. Contiene serotonina"? más allá del ropaje, formalmente (S es $\mathrm{P}$ ) no hay mayor diferencia entre una explicación y otra, ya que asignan distintos nombres a un mismo referente y, por ende, las explicaciones también son diferentes, aunque hablen de lo mismo.

En otras palabras, lo que postula la epistemología no es simplemente un diálogo entre culturas o formas de pensar, sino también un polílogo, donde todas las posturas sean respetadas, ya que lo que se busca es la construcción de una sociedad más justa e incluyente. Por eso, quizás, es que los profesores de epistemología se preocupan tanto por ser sencillos y exponer sus ideas en términos cotidianos, con el fin de que los estudiantes las comprendan y, a partir de ellas, 
puedan mejorar su entorno, haciendo de este mundo uno utópico, transformando al mundo de los hechos en la construcción de un sueño de calidad de vida, mientras que los científicos, aunque no todos, se preocupan más por palabrear su jerga excluyente de gente que no la maneja y tildarla de poco científica. Esto no es nuevo. Ya lo había explicado así, casi un siglo atrás, José Ortega y Gasset:

Claro es, yo he de hacer el más leal esfuerzo para que a todos ustedes, aun sin previo adiestramiento, resulte claro cuánto diga. Siempre he creído que la claridad es la cortesía el filósofo, y, además, esta disciplina nuestra pone su honor hoy más que nunca en estar abierta y porosa a todas las mentes, a diferencia de las ciencias particulares, que cada día con mayor rigor interponen entre el tesoro de sus descubrimientos y la curiosidad de los profanos el dragón tremebundo de su terminología hermética. Pienso que el filósofo tiene que extremar para sí propio el rigor metódico cuando investiga y persigue sus verdades, pero que al emitirlas y enunciarlas debe huir del cínico uso con que algunos hombres de ciencia se complacen, como Hércules de feria, en ostentar ante el público los biceps de su tecnicismo?.

Otro ejemplo que sirve para ilustrar aquello de lo que se ha venido disertando: el científico asume que si frota su cabello con una peinilla de plástico y luego la acerca a unos papelitos, estos se le van a adherir por causa de la excitación de los átomos llevada a cabo en el frotamiento. Ante la pregunta de un niño sobre por qué los papeles se pegan a la peinilla, la respuesta obvia, evidente y comprobada mediante un método que garantiza la objetividad y la exactitud es que los átomos son ese pegamento. Él cree esa historia. No la cuestiona porque es un dogma de la fe científica, sino que la da como un hecho irrefutable. Pero no se da cuenta que hay diferencia entre el hecho y la teoría desde la cual lo analiza. En cambio, el epistemólogo tiene más elementos para darse cuenta de que, en el fondo, no hay mayor diferencia entre la creencia del científico y la creencia del creyente medieval, de que los papeles se unen a la peinilla por causa de los ángeles. Ambas posturas son coherentes, dado que responden a la lógica que usan. Claro, el científico dirá que es absurdo hablar de ángeles o duendes porque no tienen referente, es decir, son palabras que aunque pertenecen al conjunto del lenguaje, no se reflejan en el espejo del mundo de los hechos, hablando en términos del primer Wittgenstein. Si digo: "el carro es verde", según el científico, esa proposición tiene sentido porque con mi dedo, en el mundo de los hechos, puedo

9 José Ortega y Gasset, Obras completas. Tomo VII (1948 - 1958), (Madrid: Revista de Occidente, 1964). p. 280. 
señalar al carro y distinguirlo de uno rojo. Pero si digo: "el ángel de mi guarda me acompaña todo el tiempo”, ¿a dónde debo señalar?, ¿ dónde puedo ubicar empíricamente al ángel? no puedo. ¡Totazo en la mandíbula! Ahí está. Los científicos han ganado una vez más, con una arremetida contundente, una batalla argumentativa contra los metafísicos. Pero estos últimos contraatacan: ¿acaso el átomo no es también un ente metafísico?

¿El átomo es una cosa que existe en la realidad, afuera de mi mente, o es un supuesto, un concepto que solo habita en ella? de paso: ¿la realidad se refiere solo a lo fáctico?, ¿no puede referirse también a lo psíquico, lo espiritual, lo que no puede ser percibido a través de los ojos o el tacto? Josef Estermann contestaría esa pregunta de la siguiente forma: "La proposición es un juicio intelectual sobre una circunstancia en la realidad (que es tanto material, psíquica, espiritual como mental)"10. Esta cita es usada para apoyar la idea de que cometemos la falacia de reduccionismo cuando afirmamos que la realidad está constituida solamente por la materia, ya que también es síquica, mental, espiritual. En ese sentido, la epistemología es importante para todos los estudiantes de la Universidad Santo Tomás porque posibilita pensar durante un semestre en la realidad mental, en cómo el ser humano se relaciona con ese entorno que conoce a cada momento a través de sus sentidos. Vivir es estar en permanente percepción sensorial, que es la base del conocimiento intelectual. Entonces, pensar solo en lo material o empírico sería abstenerse de vivir las demás facetas de la realidad. El especialismo iría en contra del enciclopedismo, de ver la vida en su forma integral, desde la totalidad, que es lo propio de la filosofía en tanto que madre y soporte de las ciencias, al contrario de las ciencias particulares. Pero, volviendo al tema: ¿no es el átomo, simplemente, un modelo para explicar el mundo de los hechos, mas no el mundo de los hechos mismo?, ¿no hay diferencia entre el modelo atómico de Bohr y el de Dalton? Si unos científicos afirman que el átomo es así, pero otros que es de esta otra manera, ¿dónde quedan la objetividad y la exactitud?, ¿cuál certeza puedo tener acerca de la existencia de los átomos? Lo que hay que reconocer es que tanto la postura angelical como la atómica cumplen con normas de validación, que responden, como lo diría Thomas Kuhn en La estructura de las revoluciones cientificas, a que los criterios de validez y verdad son contextualizados, correspondientes a una época, a un mundo, a una forma de pensar que no siempre es igual, que no todas las veces coincide con las demás maneras de hacerlo. De esta manera, la clase de epistemología ayuda a los estudiantes a desacralizar a la ciencia, a no creer que todo lo que se diga, por estar comprobado científicamente, es conveniente. Las normas también pueden validar

10 Josef Estermann, Curso integral de fllosofía desde América Latina. Tomo I. (Quito: Ediciones Abya-Yala, 2002), p. 31. 
prácticas inconvenientes para el ser humano y su entorno. Por cumplir las normas acríticamente, muchos alemanes terminaron favoreciendo y legitimando al régimen nazi.

Así, el epistemólogo se da cuenta de que el científico en verdad no comprobó la existencia de los átomos. Al frotar la peinilla en su cabello, evidenció que hay algo que causó el efecto de que los papeles fueran atraídos por la peinilla. A ese algo lo llamó: atracción atómica. Pero el teólogo medieval la llamaba poder divino, angelical. ¿Cuál de los dos tiene la razón? Ambos, dado que ninguna de sus teorías son verdaderas, ya que estas no pueden ser verdaderas ni falsas, tema que solo corresponde a las premisas. Más bien, las teorías son válidas o falaces. En este caso, ambas están bien argumentadas, por lo cual son válidas. Claro, uno puede sentirse más atraído hacia la ciencia que hacia la mitología, pero eso no significa que esta última deba quedar descartada, más aún cuando no hay manera de comprobar que esa fuerza que une a los papeles se llama átomo y no ángel. Si se observan las características de los ángeles, descritas por pensadores medievales, ¿no hay similitud con las características de los átomos? ambos representan a lo que científicamente se conoce como energía y que desde la mitología podría ser el obrar de los dioses. Ambos conceptos sirven para explicar por qué los papeles se pegan a la peinilla, o sea, ambos cumplen una función semejante.

Entonces, ¿qué es lo que cambia en estas dos explicaciones o interpretaciones acerca del mismo hecho? El axioma, el punto de partida. El axioma teleológico permite al teólogo pensar en un Dios que organiza de manera lógica el mundo de los hechos, haciéndolo coincidir con los planes originales que residen en su mente. Esta es la verdad medieval. El axioma de la ciencia, por su parte, posibilita al científico pensar en un universo caótico que se organiza de manera lógica, sin que alguna deidad esté llevando plan alguno, muy a pesar de que, curiosamente, los planetas son esféricos y no cúbicos, por ejemplo. Lo que cambia en ambas posturas es el enfoque. Desde el enfoque científico o moderno se considera que el hecho de que Marte sea como una pelota y no como una pirámide se debe a causas intrínsecas a dicho planeta, más no a un dios externo que le dio esa forma. Esto se conoce como mecanicismo (Galileo o Hobbes, por ejemplo), es decir, como aquella capacidad que tienen los cuerpos de moverse y funcionar por sí mismos, de manera automática, tal como funcionan los aparatos técnicos de la modernidad, hechos a imagen y semejanza de esa idea de autonomía y de odio o rechazo a la heteronomía, a la dependencia del otro. Entre tanto, desde el enfoque teológico o medieval se cree que los planetas son esféricos porque Dios, en su infinita voluntad, así lo quiso y por eso, el planeta es verdadero si él, en tanto que producto del artista cósmico, coincide con su plan divino que tenía desde antes de la fundación del mundo. O sea, lo que diferencia a la explicación de la ciencia de la teológica es el nombre que se usa: "átomo" y la manera de llevar a cabo la explicación del 
mundo de los hechos: "método científico". Pero, por más metódica que sea la ciencia, a la cual le importa más el cómo que el qué, de todos modos jamás alcanza a tocar al mundo de los hechos mismo, tal como es. Por dicha razón, ¿por qué poner al mundo de los hechos por encima de la mitología, de las explicaciones indígenas? No hay razón alguna. Lo único que se puede decir es que los europeos piensan que por poder conquistar violentamente un territorio, tienen derecho a menospreciar las formas de ser y comprender el mundo que tienen los demás pueblos. De esta forma, los estudiantes de epistemología reconocen la necesidad de valorar los saberes ancestrales como válidos e importantes para el mundo actual, no solo por sus aportes ecológicos, en lugar de continuar considerando al pensamiento europeo como el único paradigma justificado para comprender el mundo.

El problema, por ende, no es que unas culturas digan la verdad y otras, la mentira. El lío es que la forma científica y moderna de pensar se ha erigido en el mundo entero como la única posible. Cuando las explicaciones occidentales desplazan a las demás visiones del mundo, estamos hablando de eurocentrismo, concepto relevante para la filosofía latinoamericana, que a su vez permite entender por qué habitualmente se parte la historia en cuatro momentos que, curiosamente, responden a las etapas históricas de Europa. Desde esa perspectiva, y con mucha facilidad, se afirma que el saber indígena es pseudocientífico, poco fiable, encasillable en el concepto de doxa, de opinión o chisme o habladuría o información poco durable. Obviamente, también se considera a la ciencia como un conocimiento epistemológico, serio, verosímil y duradero. Pero, ¿y si volteamos la tabla?, ¿si consideramos que son los occidentales quienes se han apropiado de los saberes de otras culturas, robándoselos? Para un laboratorista alemán es muy fácil decir que el chamán es pseudocientífico. Pero no es tan fácil para él reconocer que los componentes químicos que ha investigado últimamente para sanar gente no son descubrimientos, sino lo que en Occidente se conocería como plagio, en este caso, del saber indígena. Como se había mencionado con anterioridad, la ciencia deposita su confianza en la aparente objetividad y exactitud que da su método. Por cuanto el sabio indígena no cuenta con un laboratorio científico ni conoce cuáles son los pasos validados por una comunidad académica occidental, entonces no puede -y quizás ni le interese hacerlo- patentar su saber. Pero el laboratorista alemán sí puede patentar ese conocimiento, así no sea suyo, por el simple hecho de llevar las plantas medicinales -que desde épocas ancestrales ha usado el chamán- a un microscopio, siguiendo métodos de comprobación. Como el laboratorista sí tiene cómo garantizar, o al menos responder ante una demanda, que el producto servirá para curar, podrá patentar su “descubrimiento". Desde antaño Occidente se ha quedado con los recursos naturales de los indígenas, con sus saberes, y los ha tildado de ignorantes. 


\section{Conclusiones}

En la actualidad, el ser humano está atravesando por una crisis epistemológica casi imperceptible, debido a que la información y la tecnología cambian muy rápido y las personas no pueden digerirlas con el debido tiempo que un juicio crítico requiere. Hoy, la mayoría de personas vive ocupada, corriendo de un lado para otro, atrapada en una cotidianidad sin sentido, repitiéndola vez tras vez, intentando hallar la razón de ser en el consumo de mercancías para justificar el tiempo dedicado a producir dinero, repitiendo sin pensar lo que otros dicen, al tiempo que se cree libre y culta por hacerlo. De repente, a ese vacío que es lo real se aproximan unas preguntas epistemológicas: ¿por qué hay algo y no nada?, ¿por qué lo que hay está ordenado, en lugar de ser caótico?, ¿ese orden está en la naturaleza, de tal manera que las cosas son tal como las perciben mis sentidos? o ¡ese orden está en mi mente, de tal forma que ella organiza los datos caóticos y contradictorios que los sentidos emiten acerca del mundo de los hechos?, ¡existe el mundo de los hechos o es producto de mi imaginación?, ¿yo soy libre o todo está predeterminado?, si soy libre, ¿por qué tengo obligaciones?, y si todo está diseñado de antemano por un dios o un principio cósmico ordenador, ¿qué sentido tiene soñar, calcular, pensar en un cambio, si ya todo está escrito?, si no existe la libertad ni la predestinación, sino que ambos son constructos mentales de una cultura, ¿debo vivir sometido al instinto como los animales, desconociendo todo vestigio de cultura, tal como lo proponía la ética cínica? o ¡es mejor someterme al mundo de los hechos porque él no va a mejorar jamás, tal como lo postulaban los panteístas estoicos?, ¿debo hacer una rebelión a partir de mis pensamientos o mejor debo validar el Statu Quo, que es el que me da de comer?, ¿debo denunciar aquellas actos cometidos por otros que atentan contra la moral o debo ayudar a encubrirlos?, ¿qué es lo sabio en cada caso?, ¿cómo episteme me puede ayudar a acercarme a Sofía?

En ese sentido, la epistemología ayuda a rescatar lo que nos hace humanos y nos diferencia de las máquinas, en una época en la cual el ser humano se siente cómodo siendo tratado como máquina, siendo cosificado, objetualizado, tratado sin dignidad. Hay millones de personas trabajando en maquilas y el comercio justo esperando a ser empleado por el resto de seres humanos que podrían salvar de la esclavitud a sus congéneres. Así, la epistemología funciona también como una denuncia profética ante el abuso de poder por parte de quienes son dueños del conocimiento, proponiendo alternativas de cambio con el fin de que las personas no sufran tantas vejaciones justificadas por el mito progresista de la ciencia occidental. 


\section{Referencias}

Cruz, Danilo. Filosofía sin supuestos. Manizales: Editorial Universidad de Caldas, 2001.

Dancy, Jonathan. Introducción a la epistemología contemporánea. Madrid: Tecnos, 1993.

Descartes, René. Meditaciones metafisicas y otros textos. Madrid: Editorial Gredos, 1987.

Estermann, Josef. Curso integral de filosofia desde América Latina. Tomo I. Quito: Ediciones Abya-Yala, 2002.

Wacquant, Loïc. Pensamiento crítico y disolución de la doxa: entrevista con Loïc Wacquant. Antípoda. Revista de antropología y arqueología $\mathrm{N}^{\circ} 2$ (2006): 43-50.

Nietzsche, F. Sobre verdad y mentira en sentido extramoral. Madrid: Tecnos, 1998.

Ortega y Gasset, José. Obras completas. Tomo VII (1948 - 1958). Madrid: Revista de Occidente, 1964. 